\title{
The selection criterion of injection temperature pair for transient liquid crystal thermography on film cooling measurements
}

\author{
Di Ai, Pei-Pei Ding, Ping-Hei Chen * \\ Department of Mechanical Engineering, National Taiwan University, No. 1, Sec. 4, Roosevelt Road, Taipei 10617, Taiwan, ROC
}

Received 19 October 1999; received in revised form 28 April 2000

\begin{abstract}
For the general application of liquid crystal thermography on film cooling measurement, two separate tests with different injection flow temperature rises are conducted under the same free-stream temperature and flow conditions. Therefore, a pair of equations for the two separate test conditions is solved to obtain heat transfer coefficient and film cooling effectiveness. An error could possibly occur in evaluating the film cooling effectiveness if an improper pair of injection temperatures was chosen. To reduce the data reduction error, a better mean to select an adequate pair of heated injection temperatures is recommended in current study. (c) 2001 Elsevier Science Ltd. All rights reserved.
\end{abstract}

\section{Introduction}

Recently, the transient liquid crystal thermography is popularly introduced in the film cooling measurement that is classified as a three-temperature system (freestream temperature, wall temperature and injection flow temperature) in heat transfer studies. For the unknown heat transfer coefficient and film cooling effectiveness at every fixed measured position, two equations are needed to solve the two parameters. Correspondingly, two experimental tests with different local fluid temperatures, which may produce different temperature responses of the test surface, are conducted to construct the two equations. Therefore, this "two-test method" is the basic theoretical formulation for the transient liquid crystal thermography of a three-temperature system [1]. The different local fluid temperatures are achieved by altering the injection flow temperature under fixed free-stream conditions.

The present study addresses the effect of the chosen injection temperature pair on the film cooling effectiveness result, since it might possibly cause significant error

\footnotetext{
${ }^{*}$ Corresponding author. Tel.: +886-2-27523501; fax: +886-223671755.

E-mail address: phchen@ccms.ntu.edu.tw (P.-H. Chen).
}

but was disregarded in the prior studies. The pair of different injection temperatures is generally chosen at temperatures near the two characteristic temperatures, which are the free-stream temperature and initial temperature of test piece. In general, one of the characteristic temperatures is normally preserved at room temperature for convenience [2-6].

Another method to reduce the error caused by injection temperature is the "multi-test regression method". Drost et al. [7] had carried out 6 to 8 tests by varying injection temperatures over a range of $50^{\circ} \mathrm{C}$. The experimental process and data analysis are more complicated than two-test method.

In this paper, a flat plate film cooling model $(P /$ $d=3, M=0.5, R e_{\mathrm{d}}=2200$ ) with a row of injection holes (spanwise angle $\beta=0^{\circ}$, inclination angle $\gamma=35^{\circ}$ ) is used to investigate the effect of chosen injection temperature pair on film cooling effectiveness in the two-test method of transient liquid crystal thermography. Eight tests of different injection temperatures were conducted. The injection temperatures were widely varied in a range of $50^{\circ} \mathrm{C}$ among these tests. By taking two tests as a "test set" of the two-test method, the permutation and combination of the eight tests with different injection temperatures forms 28 test sets. The 56 equations of these test sets (two equations for 


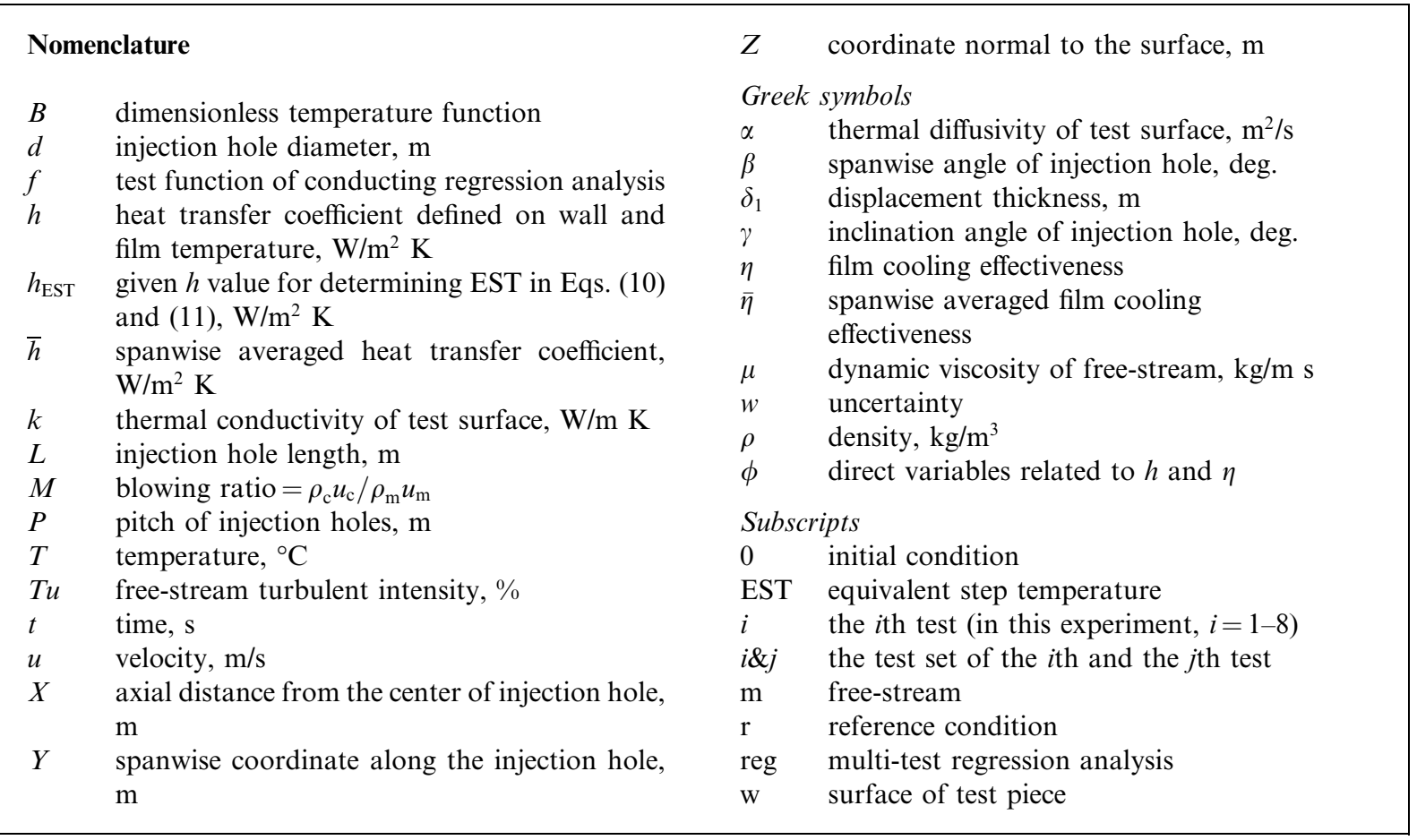

each test set) were all simplified by the "equivalent step temperature" (EST) method [8] and discussed systematically. The regression results for the eight tests were also shown for comparison. The present results show that the injection temperature pair has to be properly chosen to determine an accurate and reasonable heat transfer coefficient and film cooling effectiveness. A better tactic is also found to reduce the system error by understanding the system characteristics for the two-test model of transient liquid crystal thermography.

\section{Theory}

\subsection{Theoretical analysis}

In film cooling measurement, the temperature field is a three-temperature system and consists of the freestream temperature $T_{\mathrm{m}}$, wall surface temperature $T_{\mathrm{w}}$ and injection flow temperature $T_{\mathrm{c}}$. The physical model of the transient liquid crystal thermography can be simplified and described by a transient, one-dimensional heat conduction equation with constant property over a semi-infinite solid

$\frac{\partial^{2} T}{\partial Z^{2}}=\alpha \frac{\partial T}{\partial t}$ with boundary conditions

$Z=0, \quad-k \frac{\partial T}{\partial Z}=h\left(T_{\mathrm{w}}-T_{\mathrm{r}}\right)$,

$Z \rightarrow \infty, \quad T=T_{0}$,

and initial condition

$t=0, \quad T=T_{0}$,

where $T_{0}$ is the initial temperature of the wall and $T_{\mathrm{r}}$ is the reference temperature, which will be the film temperature that drives the heat transfer phenomenon.

The temperature variation versus time on the wall surface, where the liquid crystal is sprayed in the experiment, is the solution at $Z=0$. That is

$\frac{T_{\mathrm{w}}-T_{0}}{T_{\mathrm{r}}-T_{0}}=1-\exp \left(\frac{h^{2} \alpha t}{k^{2}}\right) \operatorname{erfc}\left(\frac{h \sqrt{\alpha t}}{k}\right)$.

With film cooling effect, $T_{\mathrm{r}}$ can be expressed as

$T_{\mathrm{r}}=(1-\eta) T_{\mathrm{m}}+\eta T_{\mathrm{c}}$,

where the film cooling effectiveness $\eta$ is defined as

$\eta=\frac{T_{\mathrm{r}}-T_{\mathrm{m}}}{T_{\mathrm{c}}-T_{\mathrm{m}}}$.

To simplify Eq. (4), define a function $B$ as

$B(x)=1-\exp \left(x^{2}\right) \operatorname{erfc}(x)$. 
Eqs. (5) and (7) are substituted into Eq. (4), which becomes

$$
\frac{T_{\mathrm{w}}-T_{0}}{\eta\left(T_{\mathrm{c}}-T_{\mathrm{m}}\right)+T_{\mathrm{m}}-T_{0}}=B\left(\frac{h \sqrt{\alpha t}}{k}\right)
$$

Note that both $T_{\mathrm{m}}$ and $T_{\mathrm{c}}$ are both time-varying functions. Thus, the temperature response on wall surface could be modified by convolution integration as

$$
\begin{aligned}
T_{\mathrm{w}}-T_{0}= & {\left[\eta\left(T_{\mathrm{c}, 0}-T_{\mathrm{m}, 0}\right)+T_{\mathrm{m}, 0}-T_{0}\right] B\left(\frac{h \sqrt{\alpha t}}{k}\right) } \\
& +\left[\eta\left(\dot{T}_{\mathrm{c}}(t)-\dot{T}_{\mathrm{m}}(t)\right)+\dot{T}_{\mathrm{m}}(t)\right] \\
& * B\left(\frac{h \sqrt{\alpha t}}{k}\right),
\end{aligned}
$$

where subscript 0 represents the initial time value of function, and the symbol $*$ is the convolution operator.

Furthermore, the ESTs of free-stream ( $\left.T_{\mathrm{m}, \mathrm{EST}}\right)$ and injection flow $\left(T_{\text {c.EST }}\right)$ are respectively, defined as [8]

$T_{\mathrm{m}, \mathrm{EST}}(h, t) \equiv \frac{B((h \sqrt{\alpha t}) / k) * \dot{T}_{\mathrm{m}}(t)}{B((h \sqrt{\alpha t}) / k)}+T_{\mathrm{m}, 0}$,

$T_{\mathrm{c}, \mathrm{EST}}(h, t) \equiv \frac{B((h \sqrt{\alpha t}) / k) * \dot{T}_{\mathrm{c}}(t)}{B((h \sqrt{\alpha t}) / k)}+T_{\mathrm{c}, 0}$.

Replacing the free-stream temperature $\left(T_{\mathrm{m}}\right)$ and injection flow temperatures $\left(T_{\mathrm{c}}\right)$ in Eq. (9) by the above definitions of $\operatorname{EST}\left(T_{\mathrm{m}, \mathrm{EST}}, T_{\mathrm{c}, \mathrm{EST}}\right)$, and rearrange to obtain

$\frac{T_{\mathrm{w}}-T_{0}}{\eta\left(T_{\mathrm{c}, \mathrm{EST}}-T_{\mathrm{m}, \mathrm{EST}}\right)+T_{\mathrm{m}, \mathrm{EST}}-T_{0}}=B\left(\frac{h \sqrt{\alpha t}}{k}\right)$.

After conducting two tests, $h$ and $\eta$ in Eq. (12) can be solved by the two equations

$\frac{T_{\mathrm{w}}-T_{0,1}}{\eta\left(T_{\mathrm{c}, \mathrm{EST}, 1}-T_{\mathrm{m}, \mathrm{EST}, 1}\right)+T_{\mathrm{m}, \mathrm{EST}, 1}-T_{0,1}}=B\left(\frac{h \sqrt{\alpha t_{1}}}{k}\right)$,

$$
\frac{T_{\mathrm{w}}-T_{0,2}}{\eta\left(T_{\mathrm{c}, \mathrm{EST}, 2}-T_{\mathrm{m}, \mathrm{EST}, 2}\right)+T_{\mathrm{m}, \mathrm{EST}, 2}-T_{0,2}}=B\left(\frac{h \sqrt{\alpha t_{2}}}{k}\right) .
$$

The subscripts 1 and 2 denote the first test and the second test, respectively. A more detailed description for obtaining $h$ and $\eta$ by this EST method can be found in the work of Chen et al. [8]

\subsection{System characteristics}

The test cases in the present study were conducted with test piece remained at room temperature, fixed freestream temperature and varied injection temperatures. The characteristics of Eq. (12) with different $T_{\mathrm{c} \text {.EST }}$ are shown in Fig. 1(a)-(c). When the test conditions were varied from $T_{\mathrm{c}, \mathrm{EST}}<T_{\mathrm{m}, \mathrm{EST}}$ to $T_{\mathrm{c}, \mathrm{EST}}>T_{\mathrm{m}, \mathrm{EST}}$, the system would have constructional change. Fig. 1(a) shows the $h-\eta$ curve $C$ when the EST of injection flow is lower than the EST of free-stream. The $\eta$ value at the singular point in Eq. (12) was defined as point $Q$ and the $\eta$ value is equal to $\left(T_{\mathrm{m}, \mathrm{EST}}-T_{\text {initial }}\right) /\left(T_{\mathrm{m}, \mathrm{EST}}-T_{\mathrm{c}, \mathrm{EST}}\right)$. The curve $C$ intercepts the vertical axis at point $R$ and the $h$ value is equal to $k(\alpha t)^{-1 / 2} B^{-1}\left(\left(T_{\mathrm{w}}-T_{\text {initial }}\right) /\left(T_{\mathrm{m}, \mathrm{EST}}-T_{\text {initial }}\right)\right)$. For $T_{\mathrm{c}, \mathrm{EST}}<T_{\mathrm{m}, \mathrm{EST}}$, point $Q$ would be located on the right plane of vertical axis. When $\eta$ approaches point $Q, h$ would increase to infinity, so the curve $C$ would be an increasing function. In a physical system, $\eta$ value ranges from 0 to 1. Fig. 1(b) shows the $h-\eta$ curve $C$ when the EST of injection flow is higher than the EST of freestream. Since $T_{\mathrm{c}, \mathrm{EST}}>T_{\mathrm{m}, \mathrm{EST}}$, point $Q$ would be located on the left plane of vertical axis and the curve $C$ would be an decreasing function. For the critical point at $T_{\mathrm{c}, \mathrm{EST}}=T_{\mathrm{m}, \mathrm{EST}}$ of the system, point $Q$ does not exist. Curve $C$ will become a horizontal line as shown in Fig. 1(c) and the $h$ value is a constant. Therefore, for some cases in the two-test method of transient liquid crystal thermography, the injection temperature will be set equal to the free-stream temperature in the first test to determine the $h$ value. The obtained $h$ value will then be substituted into the equation of the second test to determine $\eta$ value $[2,3]$.

After realizing the basic system characteristics of Eq. (12), the intersection forms of the two curves for the equation set (Eqs. (13) and (14)) could be classified into three types as shown in Figs. 2(a)-(c). Figs. 2(a) and (b) represents test sets with injection temperatures that are

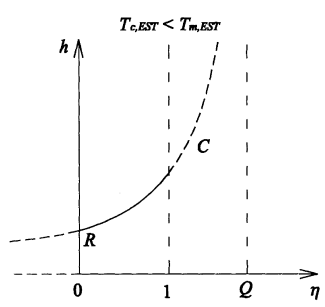

(a)

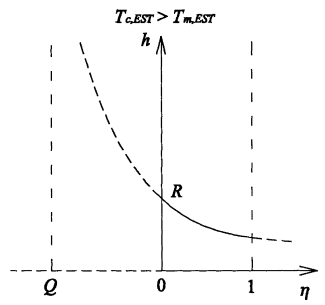

(b)

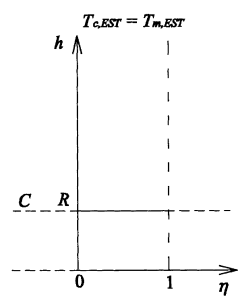

(c)

Fig. 1. The characteristics of Eq. (12). 


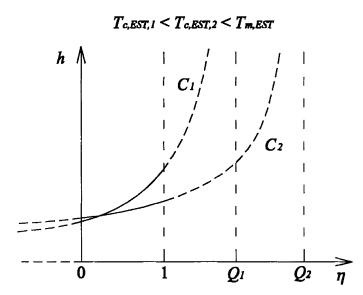

(a)

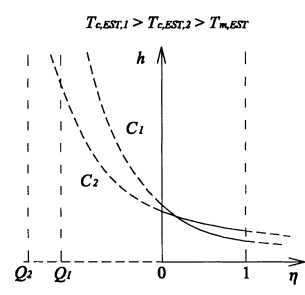

(b)

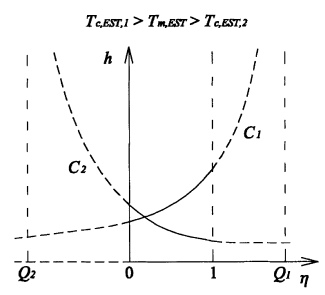

(c)

Fig. 2. The characteristics of Eqs. (13) and (14) at different injection temperatures.

both set at "the same side" of free-stream temperature. When both ESTs of injection flows are lower than the EST of free-stream with $T_{\mathrm{c}, \mathrm{EST}, 1}<T_{\mathrm{c}, \mathrm{EST}, 2}<T_{\mathrm{m}, \mathrm{EST}}$, the intersection form of curves $C_{1}$ and $C_{2}$ is shown in Fig. 2(a). A reverse situation with $T_{\mathrm{c}, \mathrm{EST}, 1}>T_{\mathrm{c}, \mathrm{EST}, 2}>T_{\mathrm{m}, \mathrm{EST}}$ is shown in Fig. 2(b). If the temperature difference of injection flow pair is too small (the included angle around the intersection point of curves $C_{1}$ and $C_{2}$ are small as shown in Figs. 2(a) and (b)), a small perturbation or any undetermined random system noise might induce the deviation of curve and cause a large deviation in result. It also implies that the coefficient matrix of the equation set has been ill-conditioned at this situation. Fig. 2(c) shows the intersection form of curves $C_{1}$ and $C_{2}$ with $T_{\mathrm{c}, \mathrm{EST}, 1}>T_{\mathrm{m}, \mathrm{EST}}>T_{\mathrm{c}, \mathrm{EST}, 2}$. Near the intersection point, one of the curves has positive slope and another with negative slope. When both $T_{\mathrm{c}, \mathrm{EST}, 1}$ and $T_{\mathrm{c}, \mathrm{EST}, 2}$ approach $T_{\mathrm{m}, \mathrm{EST}}$, both slopes will approach zero near the intersection point and the included angles will become small. Also, a slight perturbation or noise of system can induce a large deviation of result. When the temperature difference of injection flow pair is increased, the included angles between two curves will increase gradually and the effect of system perturbation on the results would become less significant.

Comparison on Figs. 2(a)-(c) shows that a large included angle between the characteristic curves will be easier to be obtained by conditions of Fig. 2(c). Therefore, the present analysis suggests that a stable result can be attained by choosing a large temperature difference for the injection flow pair with one higher and another lower than the free-stream temperature.

The selection of injection temperature pair is qualitatively described through the analysis of system characteristics mentioned above while the quantitative results will be shown in the discussions later.

\section{Test facility}

The present study used wire-screen heaters for the heating of free-stream and injection flow. The initial temperature of the test piece was maintained at room temperature. When the transient experiment is initiated, the only procedure that has to be taken is to switch on the heaters. Therefore, the flow pattern can be firmly maintained during the test. A schematic view of test facility is shown in Fig. 3(a).

The free-stream flow system was constructed by a suction type wind tunnel. A convergent nozzle with an area contraction ratio of 9:1 accelerates the free-stream air. The screen heater was designed to offer step temperature rise as perfect as possible. The heater was constructed by using high resistance, high heating response and densely interwoven heating wires of $0.1 \mathrm{~mm}$ diameter to ensure that the temperature distribution is uniform and temperature history is steady during the transient experiment. The heating wires were winded on

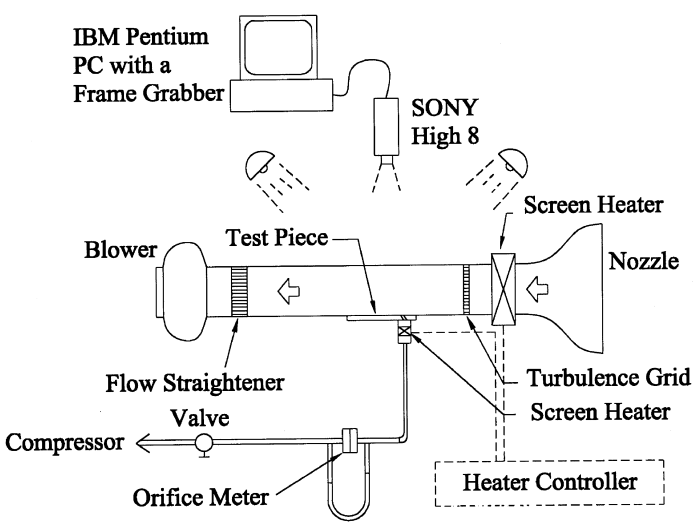

(a)
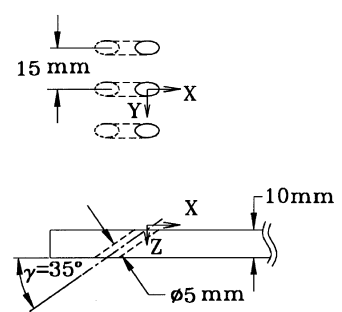

(b)

Fig. 3. (a) Schematic view of test facility; (b) cylindrical holes configuration of flat piece. 
several sensitized and etched circuit boards that were machined to fit the test section to prevent any flow disturbance. The biplanar bar-grid turbulence promoter with a porosity of $50 \%$, formed by crisscrossed $3 \mathrm{~mm}$ diameter metal cylinders, was connected behind the heater at where $45 \mathrm{~cm}$ upstream of the injection holes of test piece. The test section had a square cross-section area of $10 \mathrm{~cm} \times 10 \mathrm{~cm}$, and the flat plate test piece with coated liquid crystal was placed at the bottom wall of the test section. The test section and the test piece were made of plexiglass for the convenience of light spreading, observation, image capturing, and also to prevent any conduction loss. A flow straightener was positioned to the rear end of test section, and then an axial fan was connected as the driving source of flow field.

The injection hole configuration is shown in Fig. 3(b). The injection hole diameter is $d=5 \mathrm{~mm}$. The included angle projected in $X Z$ plane between the injection hole direction and $X$ direction is $\gamma=35^{\circ}$, and the included angle projected in $X Y$ plane between the injection hole direction and $X$ direction is $\beta=0^{\circ}$. The hole length-todiameter ratio $(L / d)$ is 3.5 and the pitch-to-diameter ratio $(P / d)$ is 3 . The analyzed region was extended to $X / d=20$.

The free-stream velocity was measured by a hot film anemometer (Dantec, Flowmeter 54N60). Both the turbulent intensity and displacement thickness of freestream were measured by a TSI IFA-100 anemometer with hot-wire probes of TSI 1210-T1.5 and TSI 1218T1.5, respectively. Transient free-stream temperature history was measured by a thermocouple and recorded by a data logger (Gulton Rustrak, Rustrak-Ranger II). All the above-described measurements were conducted at $1.5 \mathrm{~cm}$ upstream from the injection hole.

The injection flow was supplied by a reciprocatingtype compressor that provides an airflow rate of 0.0018 $\mathrm{m}^{3} / \mathrm{s}$ at an operating pressure of $7 \mathrm{~atm}$. The flow rate was adjusted by a needle valve and measured by a calibrated flange-type orifice. Passing through the orifice, injection flow entered a settling chamber. A porous plate with high flow resistance was placed in the settling chamber to assure the uniformity of injection flow during ejection. In addition, a screen heater in the chamber offers the step temperature rise of injection flow. A thermocouple was placed in the chamber to measure the temperature that was recorded continuously by a data logger.

For the image processing system, a Sony Hi8 camera captures and records the liquid crystal color change image at a rate of 30 frames/s. As the recorded tape is played, the image signals are grabbed by a frame grabber in the Pentium-II computer. The Green value based image processing software analyzes and outputs the color change time from the beginning of test to the threshold Green value of every pixel. The color change time will be used in the later analysis to determine both $h$ and $\eta$.
The captured image of liquid crystal will be clearer on a black background. Therefore, black paint was first sprayed on the back surface of the plexiglass test piece. The encapsulated liquid crystal liquid (Hallcrest, BM/ $\mathrm{R} 38 \mathrm{C} 5 \mathrm{~W} / \mathrm{C} 17-10$ ) was uniformly sprayed a thin layer of around several $\mu \mathrm{m}$ on the test surface.

The test piece with coated liquid crystal was assembled to the test section after calibration. The axial fan and compressor were adjusted, respectively to the required flow rates for the free-stream and injection flow. The transient test began when the free-stream and injection flow screen heaters were switched on. Simultaneously, the liquid crystal color change history was captured by the video camera, and the data logger recorded the transient temperature history of free-stream and injection flow.

For the data analysis, the recorded videotape was analyzed by the image processing software to obtain the color change time files of every pixel when it reached the threshold temperature. Finally, the $h$ and $\eta$ can be obtained by solving Eqs. (13) and (14) for every pixel.

\section{Experiment design}

To understand the effect of chosen pair of injection temperatures on the result of $h$ and $\eta$, eight injection flow temperatures were altered for measurement under fixed free-stream conditions.

The free-stream airflow velocity was fixed at $7.8 \mathrm{~m} / \mathrm{s}$. The free-stream Reynolds number $\left(R e_{\mathrm{d}}\right)$ based on the injection hole diameter is 2200 . The free-stream turbulent intensity $(T u)$ is $2.3 \%$, and the displacement thickness to hole diameter ratio is $\delta_{1} / d=0.22$. The blowing ratio $(M)$, defined as the momentum ratio of injection flow to free-stream flow $\left(\rho_{\mathrm{c}} u_{\mathrm{c}} / \rho_{\mathrm{m}} u_{\mathrm{m}}\right)$, was fixed at 0.5 . For the present heating system, the free-stream temperature rose to $56^{\circ} \mathrm{C}$ at about $6 \mathrm{~min}$ after the screen heater was switched on.

Eight different heating conditions of the injection flow were conducted to produce eight different step temperature rises. After the color change of liquid crystal completed, the injection temperatures for the eight tests, which vary widely in a range of $50^{\circ} \mathrm{C}$, were recorded and respectively listed in Table 1 . The four injection temperatures from Tests $1-4$ were lower than the free-stream temperature. The lowest injection temperature will be constrained by the calibrated threshold temperature of liquid crystal of $38^{\circ} \mathrm{C}$ and was set to have a difference of $20^{\circ} \mathrm{C}$ lower than the free-stream. The other four injection temperatures for Tests 5-8 were set higher than the free-stream temperature. The highest injection temperature was set to have difference of $30^{\circ} \mathrm{C}$ higher than the free-stream. All the uncertainties of experiment conditions were listed in Table 2. 
Table 1

Final temperature of injection flow temperature

\begin{tabular}{ll}
\hline Test number & Temperature \\
\hline 1 & $36^{\circ} \mathrm{C}$ \\
2 & $42^{\circ} \mathrm{C}$ \\
3 & $46^{\circ} \mathrm{C}$ \\
4 & $52^{\circ} \mathrm{C}$ \\
5 & $57^{\circ} \mathrm{C}$ \\
6 & $64^{\circ} \mathrm{C}$ \\
7 & $75^{\circ} \mathrm{C}$ \\
8 & $86^{\circ} \mathrm{C}$ \\
\hline
\end{tabular}

Table 2

Uncertainties of measured parameters

\begin{tabular}{ll}
\hline Parameters & Uncertainty \\
\hline$u_{\mathrm{m}}$ & $1.2^{\%}$ \\
$R e_{\mathrm{d}}$ & $3.4 \%$ \\
$T u$ & $4.5 \%$ \\
$\boldsymbol{M}$ & $5.3 \%$ \\
$\delta_{1} / d$ & $3.6^{\circ} \%$ \\
$T_{\mathrm{m}}$ & $0.7^{\circ} \mathrm{C}$ \\
$T_{\mathrm{c}}$ & $0.2-1^{\circ} \mathrm{C}$ \\
$T_{0}$ & $0.1^{\circ} \mathrm{C}$ \\
$T_{\mathrm{w}}$ & $0.1^{\circ} \mathrm{C}$ \\
$t$ & $0.1 \mathrm{~s}$ \\
$\sqrt{\alpha / k}$ & $3 \%$ \\
\hline
\end{tabular}

For each test case, a total number of 1320 pixels were analyzed in this experiment. The color changes are all completed within 3-7 min for the whole measurements. The most questionable Test 1 , with the longest color change time due to the lowest injection temperature, would still agree with the 1-D semiinfinite assumption by the order analysis of governing equation.

According to Eqs. (13) and (14), $h$ and $\eta$ results of 28 test sets can be determined from the permutation and combination of these eight tests, and subscript representations of the 28 test sets were listed in Table 3 . These 28 test sets were classified into seven groups for the convenience of discussions. Group 1 consisting of seven

\section{Table 3}

28 test sets formed by permutation and combination among eight tests

\begin{tabular}{ll}
\hline & Subscript representation \\
\hline Group 1 & $1 \& 2,2 \& 3,3 \& 4,4 \& 5,5 \& 6,6 \& 7,7 \& 8$ \\
Group 2 & $1 \& 3,2 \& 4,3 \& 5,4 \& 6,5 \& 7,6 \& 8$ \\
Group 3 & $1 \& 4,2 \& 5,3 \& 6,4 \& 7,5 \& 8$ \\
Group 4 & $1 \& 5,2 \& 6,3 \& 7,4 \& 8$ \\
Group 5 & $1 \& 6,2 \& 7,3 \& 8$ \\
Group 6 & $1 \& 7,2 \& 8$ \\
Group 7 & $1 \& 8$ \\
\hline
\end{tabular}

test sets, had the smallest temperature difference between the two injection temperatures of each test set. Group 7, with only one test set of subscript " $1 \& 8$ ", had the largest temperature difference for the injection temperature pair. The classification of the seven groups represents a trend of increasing injection temperature differences of test set among each group, but the injection temperature difference of each test set in the seven groups were not strictly limited by a specific temperature range.

Furthermore, the results of $h$ and $\eta$, determined by multi-test regression method among the eight tests with subscript "reg", is the comparative criterion for the 28 test sets. The multi-test regression method adopts a large temperature variation of injection flow in many tests. From the viewpoint of statistics, the $h_{\text {reg }}$ and $\eta_{\text {reg }}$ obtained by the multi-test regression method will be a more accurate and reasonable representation for the true values (practical heat transfer coefficient and film cooling effectiveness in the present study) at each pixel location as compared to $h$ and $\eta$ obtained by only two tests. The definition of the regression function is identical to the work of Drost et al. [7], but the ESTs of freestream and injection flow in each test have replaced the Duhamel's superposition calculation at every pixel to simplify the calculation procedure.

Define the $f_{i}$ function in the $i$ th test as,

$$
\begin{aligned}
f_{i}(h, \eta)= & T_{\mathrm{w}}-\left[\eta\left(T_{\mathrm{c}, \mathrm{EST}, i}-T_{\mathrm{m}, \mathrm{EST}, i}\right)+T_{\mathrm{m}, \mathrm{EST}, i}-T_{0, i}\right] \\
& \times B\left(\frac{h \sqrt{\alpha t_{i}}}{k}\right)-T_{0, i} .
\end{aligned}
$$

The regression function $F$ is defined as the square root of the squared sum of function $f_{1}-f_{8}$

$F(h, \eta)=\sqrt{\sum_{i=1}^{8} f_{i}^{2}(h, \eta)}$.

The solutions $h_{\text {reg }}$ and $\eta_{\text {reg }}$ can be obtained by finding the minimum value of $F$.

\section{Uncertainty analysis}

The uncertainty analysis was conducted on the test set of subscript " $1 \& 8$ ". According to Kline and McClintock [9], if the direct variables are partiallycorrelated, the worst-case error will be adopted to estimate the total uncertainty of the derived variables (local $h$ and $\eta$ in the present study)

$w_{h}=\sum_{\phi}\left|\left(\frac{\partial h}{\partial \phi}\right) w_{\phi}\right|$,

$w_{\eta}=\sum_{\phi}\left|\left(\frac{\partial \eta}{\partial \phi}\right) w_{\phi}\right|$, 
Table 4

Total uncertainties of $h$ and $\eta$

\begin{tabular}{lll}
\hline Nominal values & $h$ & $\eta$ \\
\hline$h=22, \eta=0.11$ & $8.1 \%$ & $10.3 \%$ \\
$h=35, \eta=0.22$ & $8.3 \%$ & $8.1 \%$ \\
\hline
\end{tabular}

where $\varphi$ represents the direct variables $\left(T_{\mathrm{w}}, T_{\mathrm{o}}, T_{\mathrm{c}, 1}, T_{\mathrm{c}, 8}\right.$, $\left.T_{\mathrm{m}}, t, \sqrt{\alpha} / k\right)$ as listed in Table 2 , and $w_{\varphi}$ represents the individual uncertainty of $\varphi$.

The total uncertainties of derived variables propagated by the uncertainties of these direct variables are shown in Table 4. At position far from the injection hole, where $h=22$ and $\eta=0.11$, the total uncertainties of $h$ and $\eta$ are $8.1 \%$ and $10.3 \%$, respectively. At the position near the injection hole, where $h=35$ and $\eta=0.22$, the total uncertainties of $h$ of $8.3 \%$ is almost unchanged but $\eta$ is decreased to $8.1 \%$. All the uncertainty analysis was considered at $95 \%$ confidence interval. The contributions of $T_{\mathrm{m}}, T_{\mathrm{o}}$ and $T_{\mathrm{c}}$ in the total uncertainty of $\eta$ are almost equal.

\section{Results and discussion}

\subsection{The convergence of $\eta$}

The $h$ and $\eta$ results of the 28 test sets were all determined. The spanwise averaged film cooling effectiveness $(\bar{\eta})$ of the seven groups are shown in Fig. 4(a)-(g), respectively. For each group in Fig. 4(a)-(g), $\bar{\eta}$ of the two-test method was compared with $\bar{\eta}_{\text {reg }}$ of multi-test regression method. In each figure, the test set with injection temperature pair that "stride across" the freestream temperature, was specially indicated by symbols to observe the convergent characteristic. As the temperature difference of the injection temperature pair increases, the $\bar{\eta}$ of two-test method gradually merge to the $\bar{\eta}_{\text {reg. }}$. The convergence phenomena of the seven groups verify the system characteristics as discussed previously.

The seven $\bar{\eta}$ curves in Group 1 are shown in Fig. 4(a). The widely spreading range of $\bar{\eta}$ represents poor accuracy, and also implies poor precision. Though some curves such as $\bar{\eta}_{1 \& 2}$ and $\bar{\eta}_{5 \& 6}$ are slightly close to the regression value $\bar{\eta}_{\text {reg }}$, but they are not reliable. According to the authors' experience, when the chosen temperatures of injection flow pair are too close, it is hard to obtain the same $\bar{\eta}$ even under the same experimental conditions. The random and unstable characteristics of the system will appear and show strong influence. A small perturbation in either injection flow temperature or system noise might cause a large bias in the results. And those rugged curves, not as smooth as $\bar{\eta}_{\text {reg }}$, also imply a large error for the $\bar{\eta}$ in Group 1. From the injection flow temperatures of the test sets in Group 1, the $\bar{\eta}_{1 \& 2}, \bar{\eta}_{2 \& 3}$ and $\bar{\eta}_{3 \& 4}$ can be grouped into system type of
Fig. 2(a), $\bar{\eta}_{5 \& 6}, \bar{\eta}_{6 \& 7}$ and $\bar{\eta}_{7 \& 8}$ belong to system type of Fig. 2(b) and $\bar{\eta}_{4 \& 5}$ has system type of Fig. 2(c). The unstable curves of $\bar{\eta}$ show that the test sets with characteristic curves of small included angle will induce error in $\bar{\eta}$ evaluating.

In Fig. 4(c), the convergence improvement is more evident by the five test sets in Group 3. The results of $\bar{\eta}_{2 \& 5}$ and $\bar{\eta}_{3 \& 6}$ which are close to $\bar{\eta}_{\text {reg }}$ seem reasonable, but they still could not guarantee the recurrence and stability.

When the temperature difference of injection flow pairs in Groups 5, 6 and 7 are further increased, the maximum bias between the $\bar{\eta}_{\text {reg }}$ and $\bar{\eta}$ curves of these groups decreases to $13 \%, 9.7 \%$ and $6.6 \%$, respectively in Fig. 4(e)-(g). In the final case in Group 7, the temperature difference of the injection flow pair is $50^{\circ} \mathrm{C}$. The criterion of convergence can just be set when the effect of temperature variation (or perturbation) of injection flow pair on the results becomes small. Four test sets of $\bar{\eta}_{2 \& 7}$, $\bar{\eta}_{1 \& 7}, \bar{\eta}_{2 \& 8}$ and $\bar{\eta}_{1 \& 8}$ that possessed large temperature differences of injection flow pair from $33^{\circ} \mathrm{C}$ of $\bar{\eta}_{2 \& 7}$ to $50^{\circ} \mathrm{C}$ of $\bar{\eta}_{1 \& 8}$, were found to have the biases lower than $10 \%$ with $\bar{\eta}_{\text {reg. }}$. These four test sets showed that when either the upper or lower boundary of injection temperature of $\bar{\eta}_{2 \& 7}$ was further extended (or perturbed), the $\bar{\eta}$ results would remain stable and stay close to $\bar{\eta}_{\text {reg }}$. Therefore, the chosen injection flow temperatures pair of $\bar{\eta}_{2 \& 7}$ can be set as the convergent criterion in the present test system. Of course, a larger temperature difference of injection flow pair is recommended for a more confirmed convergence condition. For the test conditions of $\bar{\eta}_{2 \& 7}$, one of the injection temperatures is $14^{\circ} \mathrm{C}$ lower than the free-stream temperature and another is $19^{\circ} \mathrm{C}$ higher than free-stream temperature, and a total temperature difference of $33^{\circ} \mathrm{C}$ was set for the injection flow pair. It is suggested that the two temperatures of injection flow pair should be chosen at the "different sides" of freestream temperature, which is one higher and another lower than the free-stream temperature, to obtain a stable result. This criterion on choosing injection temperature pair for the two-test method is totally different from the past experience in conventional transient liquid crystal thermography, which normally possess the system types of Fig. 2(a) or (b) with the injection temperatures at "the same side" of the free-stream temperature.

As shown in Fig. 4(g), the $\bar{\eta}$ curves of two-test method will be as smooth as the multi-test regression curve after convergence. It is proved that the increase of injection temperature difference can ensure the recurrence of test results and also improve the stability of $\bar{\eta}$ curves.

It is clear that the relation between the temperature difference of injection flow pair and the free-stream temperature causes the inaccuracy in $\eta$. This meaning is also indistinctly revealed by the product of $\eta$ and 


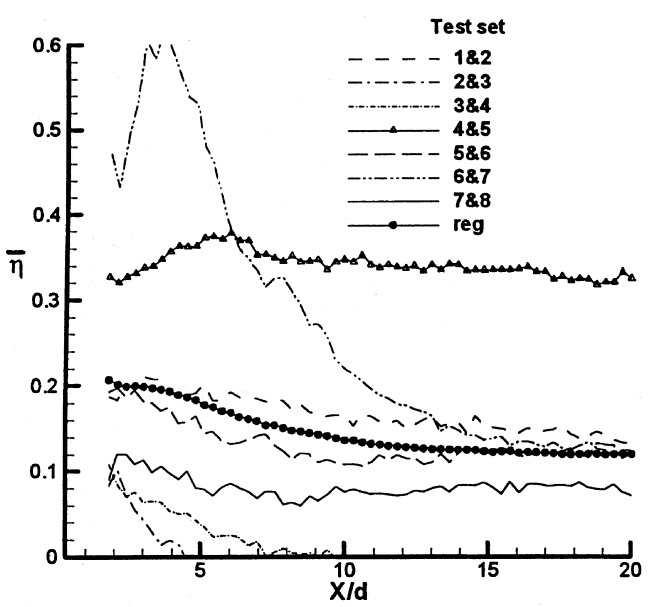

(a) Group 1

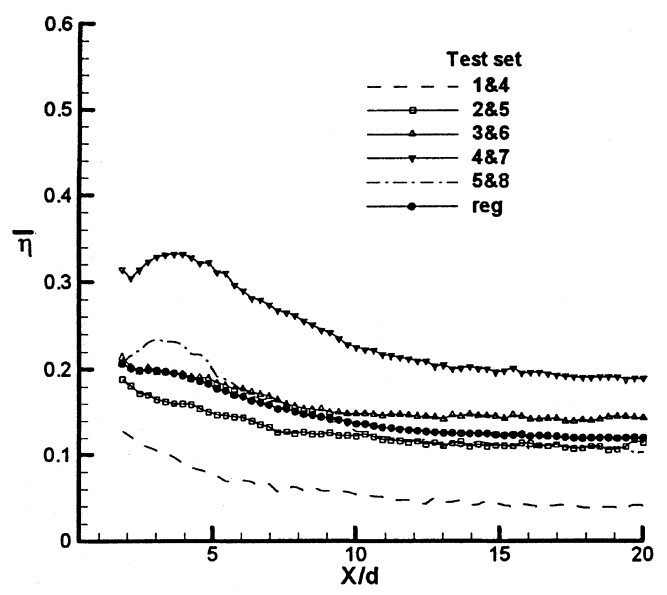

(c) Group 3

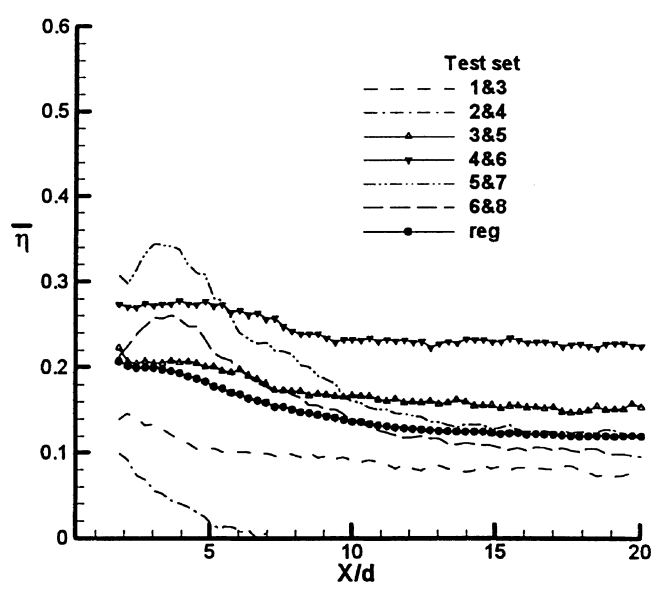

(b) Group 2

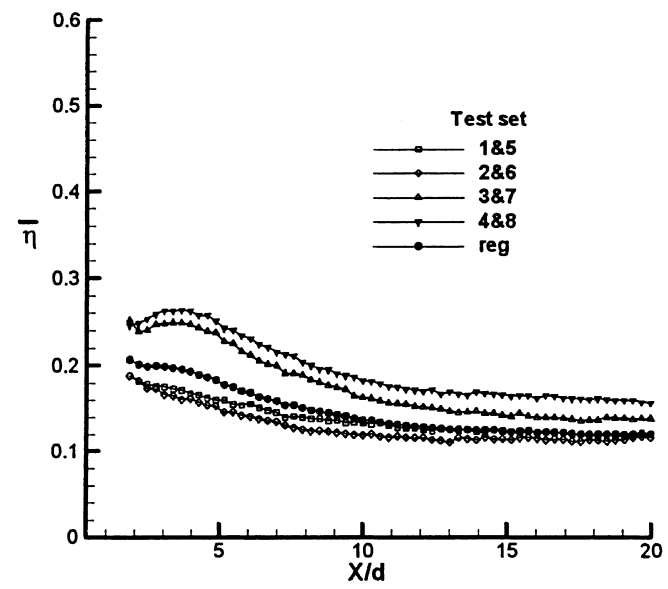

(d) Group 4

Fig. 4. The comparison between $\bar{\eta}_{\text {reg }}$ and $\bar{\eta}$ in seven groups.

temperature difference term $\left(T_{\mathrm{c} \text {.EST }}-T_{\mathrm{m} . \mathrm{EST}}\right)$ in the denominator of Eq. (12).

\subsection{The convergence of $h$}

The spanwise averaged heat transfer coefficient $(\bar{h})$ for the 28 test sets in the seven groups are compared to the regression result $\bar{h}_{\text {reg. }}$. For simplicity, only Group 1, 2, 6 and 7 are shown in Fig. 5(a)-(d). The $\bar{h}_{\text {reg value is in }}$ a range of $20-32 \mathrm{~W} / \mathrm{m}^{2}{ }^{\circ} \mathrm{C}$. When the temperature difference of injection flow pair increases, the $\bar{h}$ result will merge to $\bar{h}_{\text {reg }}$ as the $\bar{\eta}$ results discussed in previous section. However, the bias of $\bar{h}$ is not as large as the bias of $\bar{\eta}$. The perturbation effect of injection temperatures on $\bar{h}$ is less significant.
The seven $\bar{h}$ curves in Group 1 are shown in Fig. 5(a). The maximum bias is about $15 \%$. The rugged curves appear only at this stage. The six $\bar{h}$ curves in Group 2 are shown in Fig. 5(b). The maximum bias has decreased into the acceptable range of $10 \%$. The remaining groups have more accurate $\bar{h}$ results. The relations between the chosen temperatures of injection temperature pair and the free-stream temperature are not significant in Group 3 to 7 . For the four test sets of $\bar{h}_{2 \& 7}, \bar{h}_{1 \& 7}, \bar{h}_{2 \& 8}$ and $\bar{h}_{1 \& 8}$ with converged $\bar{\eta}$ curves, the results are almost merged together and the biases from $\bar{h}_{\text {reg }}$ are lower than $5 \%$.

Obviously, the random and instability of system are obvious in $\eta$ results. Relatively, the $h$ results could be regarded as independent of the chosen injection temperature pair in the measurement. Conclusively, the two 


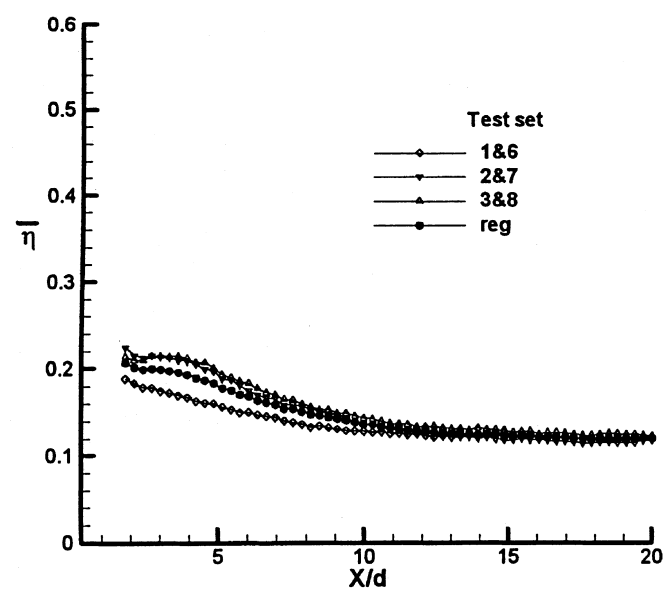

(e) Group 5

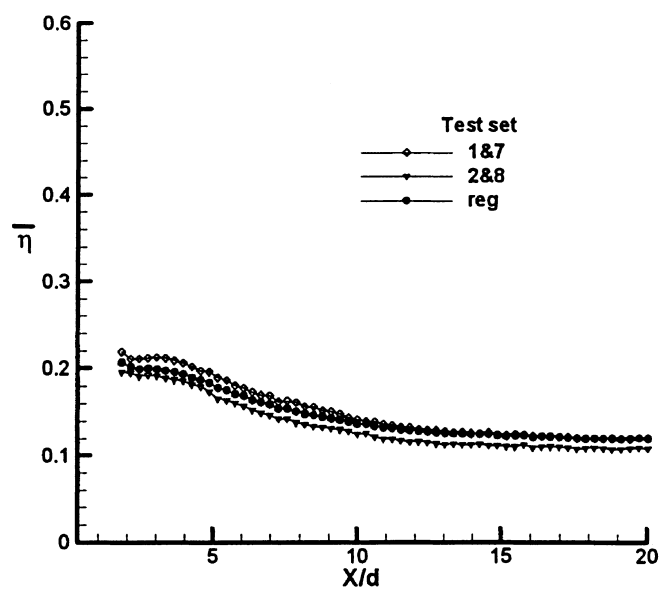

(f) Group 6

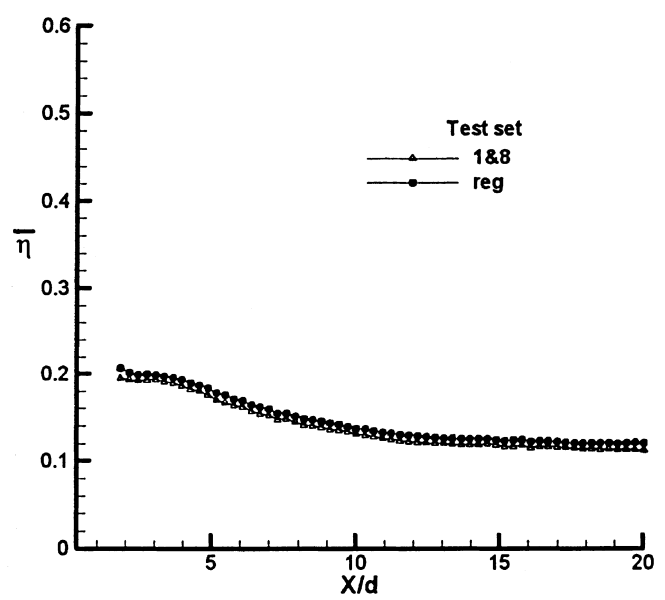

(g) Group 7

Fig. 4 (continued)

temperatures of injection flow pair in the two-test model have to be chosen carefully in order to reduce the error of $\eta$. Otherwise, the system behavior of a heat transfer/ fluid mechanics system might be misunderstood.

\subsection{The relations between the multi-test regression method and two-test method}

According to the previous discussions, when the temperature difference between the free-stream and injection flow is increased to some extent in two-test method, the results of $h$ and $\eta$ will show good agreement with the results obtained by multi-test regression analysis. If a proper injection temperature pair is chosen to obtain stable results, the results of the two- test model will be identical to the results of multi-test regression analysis. This deduces a conclusion that under the convergence condition, the results of multitest regression are only concerned with the two test conditions on the boundaries among the multi-test temperature variation range, and almost unconcerned with the middle test conditions within the range. That is, among the eight component terms of $f_{1}-f_{8}$ in the multi-test regression function $F(h, \eta)$ of Eq. (16), only the two component terms of $f_{1}$ and $f_{8}$ dominate the results. Therefore, the results of regression analysis would completely coincide with the two-test results of $h_{1 \& 8}$ and $\eta_{1 \& 8}$.

Similarly, for another convergent test set of subscript " $2 \& 7$ ", the function $F$ was reduced to six component 


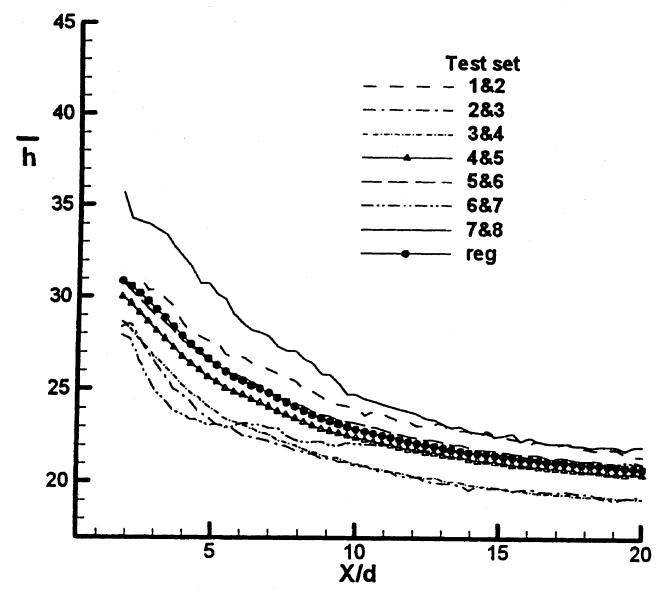

(a) Group 1

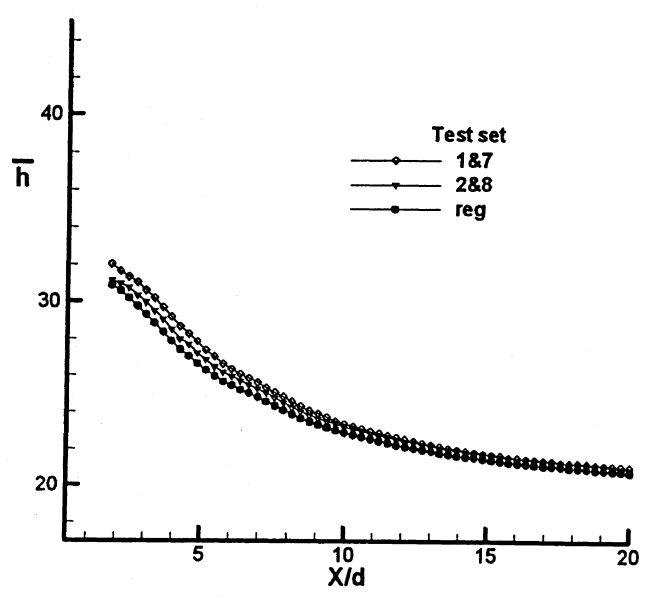

(c) Group 6

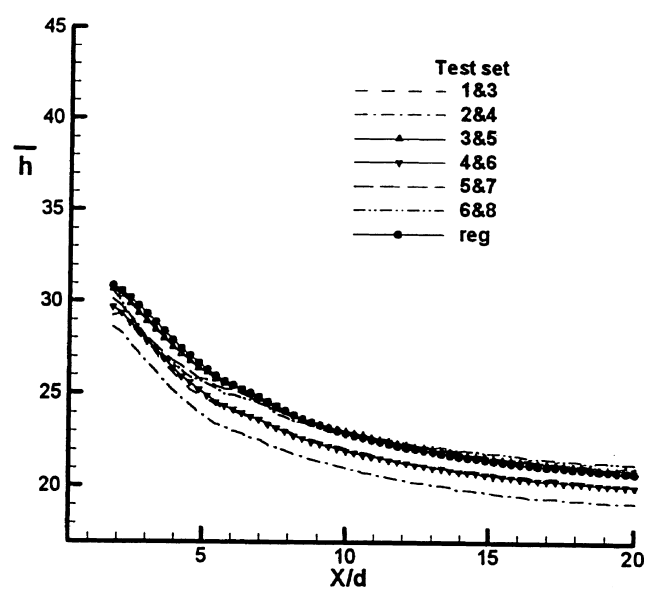

(b) Group 2

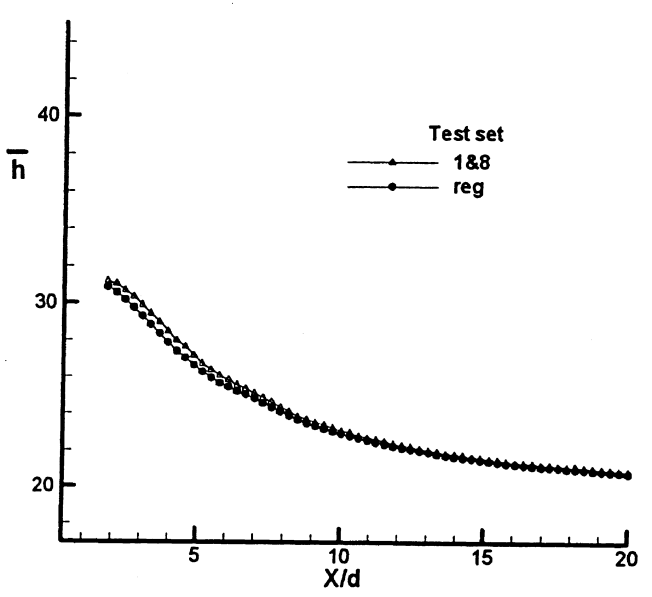

(d) Group 7

Fig. 5. The comparison between $\bar{h}_{\text {reg }}$ and $\bar{h}$ in five groups.

terms of $f_{2}-f_{7}$ to conduct the regression analysis. The same conclusion could also be made that the two component terms of $f_{2}$ and $f_{7}$ dominated the six-test regression function $F$. This conclusion was also verified by other convergent test sets, e.g., test sets of subscript " $1 \& 7$ " or " $2 \& 8$ ".

Therefore, the stable results produced by a properly chosen pair of injection temperatures also represent the results of multi-test regression analysis over this temperature range. Consequently, the system behavior has been entirely presented by the two-test method. Hence, long measurement period and data processing time could be avoided since the two-test method with proper pair of injection temperatures can produce results close to the multi-test results.

\section{Conclusions}

Film cooling measurements were conducted on a flat plate with an injection angle of $35^{\circ}, p / d=3, M=0.5$, $T_{\infty}=56^{\circ} \mathrm{C}$ and $R e_{\mathrm{d}}=2200$. Several conclusions can be drawn and given as the followings on the basis of measured results.

Comparisons were made between results obtained from each arbitrary chosen pair of film cooling tests by the two-test method and results obtained from all eight film cooling tests by using the regression approach. The comparisons show that the difference is acceptable between the two methods for the heat transfer coefficient results, but the difference will be significant in film cooling effectiveness if the heated 
injection temperatures are not properly chosen in the two-test method.

Under present test conditions, a rule of thumb is to choose a heated injection temperature that is lower than the heated free-stream temperature in the first test, and another higher than that in the second test for the analysis of two-test method. At a free-stream temperature of $56^{\circ} \mathrm{C}$, the film cooling effectiveness result obtained from a pair film cooling tests converges with result obtained from the regression of all eight tests when the heated injection temperatures of the two tests are respectively, chosen at $42^{\circ} \mathrm{C}$ and $75^{\circ} \mathrm{C}$ (test case 2\&7). Therefore, this injection temperature pair will be the convergent criterion in the present test system with a maximum bias of $10 \%$ from the regression results. The maximum bias from the regression results can be decreased to $6.6 \%$ as the two injection temperatures were set as $36^{\circ} \mathrm{C}$ and $86^{\circ} \mathrm{C}$ (test case $1 \& 8$ ), respectively.

\section{References}

[1] R.J. Vedula, D.E. Metzger, A method for the simultaneous determination of local effectiveness and heat transfer distributions in three temperature convection situations, ASME paper, 1991, 91-GT-345.
[2] H. Du, J.C. Han, S.V. Ekkad, Effect of unsteady wake on detailed heat transfer coefficient and film effectiveness distributions for a gas turbine blade, ASME J. Turbomachinery 120 (1988) 808-817.

[3] S.V. Ekkad, J.C. Han, H. Du, Detailed film cooling measurements on a cylindrical leading edge model: effect of free-stream turbulence and coolant density, ASME J. Turbomachinery 120 (1998) 799-807.

[4] S.V. Ekkad, D. Zapata, J.C. Han, Heat transfer coefficients over a flat surface with air and $\mathrm{CO}_{2}$ injection through compound angle holes using a transient liquid crystal image method, ASME J. Turbomachinery 119 (1997a) 580-586.

[5] S.V. Ekkad, D. Zapata, J.C. Han, Film effectiveness over a flat surface with air and $\mathrm{CO}_{2}$ injection through compound angle holes using a transient liquid crystal image method, ASME J. Turbomachinery 119 (1997b) 587-592.

[6] Y. Yu, M.K. Chyu, Influence of gap leakage downstream of the injection holes on film cooling performance, ASME J. Turbomachinery 120 (1998) 541-548.

[7] U. Drost, A. Bölcs, A. Hoffs, Utilization of the transient liquid crystal technique for film cooling effectiveness and heat transfer investigations on a flat plate and a turbine airfoil, ASME paper, 1997, 97-GT-26.

[8] P.-H. Chen, P.-P. Ding, D. Ai, An improved data reduction method for transient liquid crystal thermography on film cooling measurements, Int. J. Heat and Mass Transfer 44 (2001) 1379-1387.

[9] S.J. Kline, F.A. McClintock, Describing uncertainties in single sample experiments, Mech. Eng. 75 (1953) 3-8. 